\title{
Optimal Use of Echocardiography in Management of Thrombosis After Anterior Myocardial Infarction
}

\author{
Andrea Barbieri ${ }^{1}$, francesca mantovani ${ }^{2}$, Francesca Bursi ${ }^{3}$, Andrea Faggiano ${ }^{4}$, Giuseppe \\ Boriani $^{1}$, and Pompilio Faggiano ${ }^{5}$ \\ ${ }^{1}$ Azienda Ospedaliero-Universitaria di Modena Policlinico di Modena \\ ${ }^{2}$ Azienda Unità Sanitaria Locale - IRCCS Tecnologie Avanzate e Modelli Assistenziali in \\ Oncologia di Reggio Emilia \\ ${ }^{3}$ Azienda Ospedaliera San Paolo \\ ${ }^{4}$ Università degli Studi di Milano \\ ${ }^{5}$ Azienda Socio Sanitaria Territoriale degli Spedali Civili di Brescia
}

June 22, 2020

\begin{abstract}
Despite advancement in therapy and management, left ventricular thrombus (LVT) after anterior myocardial infarction (MI) is sporadically encountered and remains associated with a very high risk of major cardiovascular events and mortality. Cardiac magnetic resonance (CMR) is considered the gold standard technique for LVT detection, but it is a time consuming and expensive test not available in all centers, especially when repeated exams are necessary. Transthoracic echocardiography represents a useful tool to screen for LVT and to identify predictors of high risk of developing LVT. The advances in ultrasound technology and the use of contrast agents may potentially help clinicians to identify LVT and the use of sequential echocardiography for each patient with acute MI complicated by LVT may provide an opportunity to quantify regression and its correlation with outcomes to tailor the management of these patients. Hence, this narrative review focuses on the added value of echocardiographic-guided LVT management in patients with recent anterior MI to reduce mortality and morbidity excess related to LVT based on current evidence.
\end{abstract}

\section{Diagnosis}

A detailed assessment of LVT is crucial for patient management and prognosis. Cardiac magnetic resonance (CMR) is now considered the diagnostic standard for detection of LVT with cine-CMR and contrast-enhanced CMR (CE-CMR) being the most useful modalities (Fig.1). This is particularly true in patients with mural or small LVT. ${ }^{12}$ The only study that included surgical or pathological evidence of LVT for confirmation of LVT showed that CE-CMR has a diagnostic sensitivity of $88 \%$ and specificity of $99 \% .{ }^{13}$ No other study has subsequently shown that an alternative modality is superior to CE-CMR imaging in LVT detection. ${ }^{14}$

Cardiac magnetic resonance imaging has not only the strength to provide better spatial resolution for morphological definition ${ }^{15}$ but can characterize and differentiate the avascular LVT from neighboring structures after contrast administration. Moreover, CE-CMR can distinguish between acute versus older thrombus (Fig.1). Newer CMR sequences (such as T2* to identify ferrous products of hemoglobin breakdown and the use of long inversion time imaging to selectively null the normal myocardium) may provide further diagnostic advantages above and beyond CE-CMR imaging. ${ }^{16,} 17$

Contrast-enhanced CMR proved that an imaging delay after acute MI of more than 5 days was associated with significantly higher LVT detection rates compared to imaging performed within 5 days. Of note, 
CE-CMR performed between 9-14 days post-MI provided the highest detection rate. ${ }^{18,19}$

Despite its diagnostic superiority, CMR remains a time consuming and expensive test, not available in all centers. Indeed, it is impractical to perform and repeat CMR in all patients with high-risk MI. A more practical approach may be to perform a transthoracic echocardiography (TTE) as the first-line imaging modality to screen for LVT in all patients with recent MI. Accordingly, current European Society of Cardiology guidelines recommend routine TTE during hospital stay in all patients to exclude LVT after MI (Class I, Level B). ${ }^{20}$ Furthermore, considering that LVT could develop at various times after MI, performing repeated TTE rather than a single CE-CMR could have an even greater clinical impact in patients with satisfactory ultrasound quality.

The diagnosis of LVT by TTE should be defined as a mass in the LV cavity located adjacent to an area of LV wall dyssynergia and seen from at least two views (usually apical and short axis, Fig.2). Care must be taken to exclude the most common causes for an erroneous diagnosis of a thrombus (false tendons, trabeculae, technical artifacts and tangentially-cut LV wall). ${ }^{12}$ Usually, LVT have a homogeneous texture with a softer echo density than myocardium, which suggests that the thrombus may be relatively recent and still "in a growing phase", whereas an older thrombus tends to have a smoother surface and is typically more static. ${ }^{21}$

On the basis of available data it is possible to extrapolate that, in comparison with CE-CMR, non-contrast TTE has a sensitivity of $24 \%-33 \%$, a specificity of $94 \%-95 \%$, an accuracy of $82 \%$, a positive predictive value of $57 \%$ and a negative predictive value of $85 \% .{ }^{14}$ A low sensitivity may be of concern because TTE is the examination performed regularly in daily practice to search for LVT. However, it is difficult to generalize these data to the current "real life" since previous studies evaluating TTE used multiple gold standards, or none at all, and were conditioned by subjective image quality and the use of the off-axis projections. ${ }^{14}$ Indeed, TTE is more operator-dependent than CE-CMR. Varying gain setting and depth of field, as well as using transducers with different frequencies in multiple positions and orientations, are helpful approaches to minimize the falsepositive studies. This important notion is highlighted by the finding that TTE performance varies highly according to the exam indication: if LVT search is prespecified, sensitivity is multiplied by 2 (60\% vs. $26 \%$ ) and positive predictive value by 3 (75\% vs. 21\%) as compared with unfocused routine TTE. ${ }^{22}$ When the search for LVT is prespecified in high-risk patients with recent anterior MI and low ejection fraction, the accuracy of TTE as compared with DE-CMR is even better (sensitivity and specificity 94.7\% and 98.5\%, respectively). ${ }^{19}$ Thus, we believe that the attempt to uncritically combine results from the literature to provide a summary estimate of the diagnostic accuracy of TTE might have led to inaccurate or misleading results, at least when considering Echo labs with high standards of quality in TTE. Indeed, considering the importance of the echogenicity, TTE ideally should be scored for diagnostic quality using previously validated quantitative tools. ${ }^{12}$

In short, we must emphasize that TTE accuracy can be excellent if performed specifically for LVT search with a standardized protocol and that non-visualized LVT are usually mural and small (Table).

\section{Role of new echocardiographic technologies}

Over the past decade, we have witnessed a development in the armamentarium of echocardiographic technologies capable of providing even more detailed information about LVT. Many of these features allow an integrative approach, as they combine the unique strengths of the single technologic component to achieve unprecedented improvement in our ability to diagnose LVT by TTE. Real-time three-dimensional echocardiography (RT3DE) provides an unlimited ("panoramic") number of cutting planes in all directions through a single full volume data set (Fig.3). Therefore, cropping and rotating the volumetric data set allow to obtain the perspective that best visualizes a LVT and its attachment to the LV wall. The chance to re-align the tomographic planes obtained from a RT3DE dataset reduces the risk of missing small apical thrombi due to the foreshortening of apical views with two-dimensional TTE. ${ }^{23,}{ }^{24}$ However, RT3DE does not allow to differentiate between LVT and myocardium nor to assess the changes in thrombi structure, as it is known that with RT3DE the different shades of blue/brown color give a visual perception of the depth of different structures rather than their texture. 
The advent of ultrasound contrast agents, providing the opacification within the cardiac chambers to demonstrate the avascular "filling defect" appearance of an intracardiac LVT, has been critical. ${ }^{25}$ Indeed, it is now proven that the use of ultrasound contrast agents greatly improves the diagnostic accuracy of TTE from $82 \%$ to $92 \%$ when compared to CE-CMR. ${ }^{14}$

\section{Screening algorithm}

In patients with uncomplicated anterior MI it is advised to carry out a LVT screening before discharge. Recently, a TTE-based wall motion screening algorithm for LVT has been proposed, able to assesses the extent of apical wall-motion abnormalities using the 17-segment model. Apical LV wall motion score is then calculated on non-contrast echo by summing segmental scores within the apical LV and true apex (total of 5 segments). An apical wall motion score [?]5 can identify patients with a high likelihood of LVT, thus to be referred eventually for CE-CMR with a high diagnostic yield, regardless of LV global contractile function. ${ }^{16}$ Therefore, given cost containment, a pre-discharge TTE-based screening approach should be implemented: contrast-enhanced TTE could be performed instead of CE-CMR in all patients with high-risk apical wall motion score, especially in patients with poor ultrasound windows, and a CE-CMR could be reserved only when contrast-enhanced echo is non-conclusive. However, considering that the hospital stay of patients with uncomplicated MI has declined substantially in recent years ${ }^{26}$ and therefore is shorter than the time needed for a LVT to be detected ${ }^{26}$, it may be reasonable to repeat a TTE during the second week in patients with high-risk apical wall motion abnormality without LVT on initial imaging.

The alternative approach is to perform CE-CMR to all patients with high-risk apical wall motion score at non-contrast TTE. Of note, no specific screening pathway after anterior MI has been prospectively validated, therefore further validation before widespread application is required. A recent single-center retrospective case-match study showed that, despite contemporary antithrombotic treatment, a LVT detected by CECMR, but not by contrast TTE, is associated with a similar 4-fold long-term higher risk of embolism compared with matched non-LVT patients. ${ }^{27}$ However, this study evaluated a heterogeneous cohort where only one-third of patients had a previous MI with a severely reduced ejection fraction. Because of the retrospective nature of the study, referral bias was inevitable and it was not feasible to obtain reliable measures of the efficacy of anticoagulation, such as the time in therapeutic range, in all LVT patients. Therefore, to address all these limitations, more studies are needed specifically comparing screening strategies based on contrast TTE or CE-CMR for detection of LVT in patients with recent anterior MI.

\section{Risk stratification and prevention of systemic thromboembolism}

Even in the primary angioplasty era, LVT formation after MI indicated a fourfold increased embolic risk and twofold long-term mortality rate. ${ }^{28}$ The risk of embolic events is the highest during the first or second week after MI with a decline over the subsequent 3 months. ${ }^{29-31}$ Thrombi prone to embolization are those that protrude in the LV cavity (exposed to the blood flow on several sides) and have a free mobility (which indicates thrombus friability), unlike the mural thrombi that appear flat and parallel to the endocardial surface (Fig.2). ${ }^{32,33}$

Other echocardiographic LVT characteristics, such as thrombus size, central echolucency or hyperkinesia of the myocardial segments adjacent to the thrombus, were found to be associated with an increased risk of embolism in some studies, but were not confirmed by others. ${ }^{1}$ However, it is critically important to appreciate that a spontaneous time-course variation in the LVT morphologic aspects is common in the first several months after MI (Fig.3). Importantly, up to $40 \%$ of embolism episodes occur in patients whose thrombi are neither protuberant nor mobile. ${ }^{34}$ Therefore, when LVT is detected, anticoagulation is essential to prevent systemic thromboembolism regardless of the echocardiographic phenotype.

Current guidelines recommend vitamin $\mathrm{K}$ antagonists as the first-choice therapy in this patient population. ${ }^{20,35,36}$ Thrombus resolution with warfarin occurs frequently (80-85\% at 6 months) after an anterior MI. It could be argued that LVT regression may be at least partially the consequence of thrombus embolization. However, although asymptomatic embolization cannot be excluded, LVT regression seems not associated with increased embolic risk. ${ }^{37}$ 
The thromboembolic risk appears to be lower in the current reperfusion era, with a cumulative incidence of $5.5 \%{ }^{6}$ This is due, at least in part, to the higher time in therapeutic range usually achieved during warfarin treatment. Indeed, the rate of systemic embolism is quite low (3\%) in patients with a time in therapeutic range $[?] 50 \%{ }^{38}$

Of note, no data are currently available from clinical trials evaluating the safety and efficacy of anticoagulation in the treatment of LVT after MI. This gap in knowledge is important considering that the antithrombotic options for LVT have become more complicated for a series of reasons, including patient characteristics, with progressively older subjects, affected by multiple comorbidities, the need for a combination of chronic anticoagulation and various antiplatelet therapy schemes, and the emergence of direct oral anticoagulants (DOACs), widely used in the setting of thromboembolic prophylaxis for atrial fibrillation or pulmonary embolism. Therefore, clinicians must rely on available data from trials to guide the treatment of these different thromboembolic conditions, which substantially showed that the combination of oral anticoagulants with two antiplatelets (triple therapy) increases the bleeding risk compared with less potent antithrombotic regimens after MI. On the other hand, observational data suggest that triple therapy regimens may not prevent LVT formation. ${ }^{21,39}$

The efficacy of DOACs in the treatment of LVT seems comparable to the efficacy of warfarin, but current data are limited to small case series and meta-analysis of case reports ${ }^{40-42}$. Nevertheless, the intrinsic differences in thrombogenesis between LVT and atrial fibrillation-related thrombi, either in the left atrium and its appendage, can make anticoagulants non-interchangeable and request a better assessment of the off-label use of DOACs in terms of benefits and risks. Indeed, the largest multicenter, retrospective study for LVT diagnosed by TTE argues against the assumption of equivalence between DOACs and warfarin. ${ }^{43}$ Trials comparing DOACs and warfarin in the treatment of LVT are ongoing in China, Malaysia and Israel (ClinicalTrials.gov number NCT03764241, NCT02982590 and NCT03232398, respectively).

\section{Echocardiography and clinical management}

In patients with recent anterior MI and high-risk non-contrast apical wall motion score ([?]5), pre-discharge image enhancement with ultrasound contrast agents is recommended in the absence of contraindications. In those without LVT, one approach may involve a repeated TTE after [?] 2 weeks (Fig.4). If LVT is not detected on repeated TTE, anticoagulants are not indicated. ${ }^{44}$ Conversely, in the case of detection of LVT, oral anticoagulants should be immediately started with a parenteral anticoagulant bridging. A combination of warfarin with single P2Y12 inhibitor (double therapy) may be preferred over triple therapy, in light of accumulating evidence suggesting the reduced bleeding risk of this approach from studies on patients with atrial fibrillation associated with acute coronary syndrome. ${ }^{39}$ Hence, when used in combination with an oral anticoagulant, clopidogrel should be preferred above aspirin and more potent P2Y12 inhibitors. In patients at high risk of recurrent MI or stent thrombosis, a short course (e.g., 1 month) of triple therapy might be considered when balanced against the bleeding risk.

In patients with difficulty to maintain the therapeutic anticoagulation range with warfarin a full-dose DOAC may be preferred. ${ }^{21}$

The optimal duration of oral anticoagulation in patients with LVT after MI has never been tested in the era of dual antiplatelet therapy. According to current guidelines, anticoagulants should be added to antiplatelet therapy for a variable time of 3-6 months since the duration must be individualized according to bleeding risk. ${ }^{20}, 35,36$ At the end of this period, a repeated TTE with ultrasound contrast agents should be performed. If the LVT has resolved, anticoagulants can be dismissed while continuing DAPT. Nevertheless, a prudent approach with an additional TTE with ultrasound contrast after a further 3 months is suggested. In the case of LVT recurrence at any time, long-term anticoagulation must be maintained unless other contraindications. In patients without LVT resolution or persistent apical spontaneous echo-contrast, the optimal therapeutic management is unclear, and decision regarding continuation of oral anticoagulation should be made on a case-by-case basis (Fig.3).

Recently, a real-world post hoc analysis from a single-center study with independently verified LVT (mainly 
diagnosed by TTE) indicated that thrombus regression, which occurred in $62.3 \%$ of cases, represents a strong independent marker of lower morbidity and mortality. Conversely, patients with persistent LVT were at high risk of clinical complications even when combining with antiplatelet agents. ${ }^{11}$ The observation that in this cohort as many as $1 / 3$ of patients did not achieve total LVT regression and that even $14.5 \%$ had recurrent or increased size of LVT emphasize the need for more efficient therapeutic strategies to improve and accelerate LVT regression. Yet, any intensification of the antithrombotic treatment may be compromised by more frequent and more severe bleeding complications. Therefore, an individualized risk stratification based on patient characteristics and LVT evolution under TTE guidance could be the ideal decision-making approach. However, only a prospective, randomized controlled trial may detect and quantify the advantages of anticoagulation intensification versus long-term maintenance of standard anticoagulation in these cases.

\section{Conclusive remarks}

Current echocardiographic-guided screening and management strategies for LVT in patients with recent anterior MI warrant to be re-evaluated in light of the advances in technology which greatly improve the diagnostic accuracy of this approach as compared to CE-CMR. However, this pathway relied on resolution on TTE as evidence of treatment effect requires prospective validation since many questions, such as the prognostic significance of LVT detected by CE-CMR but not by contrast TTE, are still unanswered. In some cases, a LVT can be a marker of an increased thrombotic risk that persists at the long term, after the initial period of anticoagulation and even despite thrombus resolution by TTE. This knowledge could guide the selection of the optimal imaging modality for the screening of patients with recent anterior MI at high risk for LVT. Hopefully, this work might strengthen the role of echocardiography in the management of these patients.

\section{Disclosures:}

None

\section{Funding:}

None

\section{Figures' legend}

Figure 1. Typical example of left ventricular thrombosis assessment by dedicated cardiac magnetic resonance after anterior myocardial infarction.

Patient example. Panel A: Patients with transmural anterior infarction with older mural thrombus (low signal intensity in T1 in cine cardiac). Panel B, C: acute protruding thrombus in the left ventricular apex (yellow arrow) showing high signal intensity on T1. Panel D: phase sensitive contrast-enhanced magnetic resonance images. Panel E: contrast-enhanced magnetic resonance images: note that thrombus appears black on long inversion time (T1).

Figure 2. Different morphological left ventricular thrombi aspects detected by transthoracic echocardiography.

Panel A: 4-chamber apical view showing a left ventricular mural thrombus visible as a minus image (asterisk) because of contrast agent. Panel B: a protruding left ventricular thrombus visualized before (arrow) and after contrast injection (asterisk). Panel C: a large protruding and free mobile left ventricular thrombus before (arrow) and after contrast injection (asterisk).

Figure 3. Left ventricular apical thrombus detected by echocardiography 15 days after acute anterior myocardial infarction.

Panel A: 4-chamber and 2-chamber apical views showing a large protruding LV apical thrombus (asterisk) in an akinetic LV apex. Note soft density and irregular shape typical of recent thrombus Panel B: after contrast injection, the thrombus is visible as a minus image (asterisk). Panel C: full volume RT3D apical view oriented from the LV apex, shows the spatial definition of LV thrombus. Panel D: multislice multiplane 
view of LV apex with thrombus attached to the apical septal and apical inferior segments. Panel E: follow-up echocardiogram after 3 months of anticoagulant therapy showing almost complete resolution of the apical thrombus but residual shallow mural thrombus with smooth and hyperechogenic surface visible in the apical 2 chamber view (arrow) in the akinetic LV apex. Data on the embolic avoidance and subsequent antithrombotic management in patients who did not achieve total LVT regression are limited or lacking.

Figure 4. Transthoracic echocardiography-based flow chart for guiding LVT management after anterior myocardial infarction. Note that for many decision-making there is no scientific evidence. Therefore, the proposed algorithm is inevitably, for the most part, based on the opinion and clinical practice of the authors.

WMSI: wall motion score index; LVT: left ventricular thrombus; AC: anticoagulation therapy; TTE: transthoracic echocardiography; LV: left ventricle; SEC: spontaneous echo-contrast.

Table and table's legend

Table . Imaging modalities used to diagnose left ventricular thrombus after myocardial infarction.

\begin{tabular}{lllllllll}
\hline & Sens & Spec & PPV & NPV & Accuracy & Gold standard confirmation & Prior MI & Referen \\
\hline CE-CMR & $88 \%$ & $99 \%$ & NA & NA & NA & Surgical/Pathological & $100 \%$ & $\# 13$ \\
TTE* & $60 \%$ & $88 \%$ & $75 \%$ & $78 \%$ & $77 \%$ & CE-CMR & $100 \%$ & $\# 22$ \\
TTE* & $94.7 \%$ & $98.3 \%$ & NA & NA & NA & CE-CMR & $100 \%$ & $\# 19$ \\
Contrast TTE & $61 \%$ & $99 \%$ & $95 \%$ & $91 \%$ & $92 \%$ & CE-CMR & $83 \%$ & $\# 12$ \\
\hline
\end{tabular}

* Left ventricular thrombosis search prespecified.

**Left ventricular thrombosis search prespecified in recent anterior myocardial infarction and low ejection fraction.

CE-CMR: contrast-enhanced cardiac magnetic resonance

TTE: transthoracic echocardiography

MI: myocardial infarction

NA: not available

PPV: positive predictive value

NPV: negative predictive value

\section{References}

1. Delewi R, Zijlstra F, Piek JJ. Left ventricular thrombus formation after acute myocardial infarction. Heart . 2012;98:1743-1749

2. Chiarella F, Santoro E, Domenicucci S, Maggioni A, Vecchio C. Predischarge two-dimensional echocardiographic evaluation of left ventricular thrombosis after acute myocardial infarction in the gissi-3 study. Am J Cardiol . 1998;81:822-827

3. Keren A, Goldberg S, Gottlieb S, Klein J, Schuger C, Medina A, Tzivoni D, Stern S. Natural history of left ventricular thrombi: Their appearance and resolution in the posthospitalization period of acute myocardial infarction. J Am Coll Cardiol . 1990;15:790-800

4. Poss J, Desch S, Eitel C, de Waha S, Thiele H, Eitel I. Left ventricular thrombus formation after stsegment-elevation myocardial infarction: Insights from a cardiac magnetic resonance multicenter study. Circ Cardiovasc Imaging . 2015;8:e003417

5. van Dantzig JM, Delemarre BJ, Bot H, Visser CA. Left ventricular thrombus in acute myocardial infarction. Eur Heart J . 1996;17:1640-1645 
6. Habash F, Vallurupalli S. Challenges in management of left ventricular thrombus. Ther Adv Cardiovasc Dis . 2017;11:203-213

7. Robinson AA, Jain A, Gentry M, McNamara RL. Left ventricular thrombi after stemi in the primary pci era: A systematic review and meta-analysis. Int J Cardiol . 2016;221:554-559

8. Le May MR, Acharya S, Wells GA, Burwash I, Chong AY, So DY, Glover CA, Froeschl MPV, Hibbert B, Marquis JF, Dick A, Blondeau M, Bernick J, Labinaz M. Prophylactic warfarin therapy after primary percutaneous coronary intervention for anterior st-segment elevation myocardial infarction. JACC Cardiovasc Interv . 2015;8:155-162

9. Shavadia JS, Youngson E, Bainey KR, Bakal J, Welsh RC. Outcomes and prognostic impact of prophylactic oral anticoagulation in anterior st-segment elevation myocardial infarction patients with left ventricular dysfunction. J Am Heart Assoc . 2017;6

10. McCarthy CP, Murphy S, Venkateswaran RV, Singh A, Chang LL, Joice MG, Rivero JM, Vaduganathan M, Januzzi JL, Jr., Bhatt DL. Left ventricular thrombus: Contemporary etiologies, treatment strategies, and outcomes. J Am Coll Cardiol . 2019;73:2007-2009

11. Lattuca B, Bouziri N, Kerneis M, Portal JJ, Zhou J, Hauguel-Moreau M, Mameri A, Zeitouni M, Guedeney P, Hammoudi N, Isnard R, Pousset F, Collet JP, Vicaut E, Montalescot G, Silvain J, Group AS. Antithrombotic therapy for patients with left ventricular mural thrombus. J Am Coll Cardiol . 2020;75:16761685

12. Weinsaft JW, Kim RJ, Ross M, Krauser D, Manoushagian S, LaBounty TM, Cham MD, Min JK, Healy K, Wang Y, Parker M, Roman MJ, Devereux RB. Contrast-enhanced anatomic imaging as compared to contrast-enhanced tissue characterization for detection of left ventricular thrombus.JACC Cardiovasc Imaging . 2009;2:969-979

13. Srichai MB, Junor C, Rodriguez LL, Stillman AE, Grimm RA, Lieber ML, Weaver JA, Smedira NG, White RD. Clinical, imaging, and pathological characteristics of left ventricular thrombus: A comparison of contrast-enhanced magnetic resonance imaging, transthoracic echocardiography, and transesophageal echocardiography with surgical or pathological validation. Am Heart J . 2006;152:75-84

14. Roifman I, Connelly KA, Wright GA, Wijeysundera HC. Echocardiography vs. Cardiac magnetic resonance imaging for the diagnosis of left ventricular thrombus: A systematic review. Can J Cardiol . $2015 ; 31: 785-791$

15. Delewi R, Nijveldt R, Hirsch A, Marcu CB, Robbers L, Hassell ME, de Bruin RH, Vleugels J, van der Laan AM, Bouma BJ, Tio RA, Tijssen JG, van Rossum AC, Zijlstra F, Piek JJ. Left ventricular thrombus formation after acute myocardial infarction as assessed by cardiovascular magnetic resonance imaging. Eur J Radiol . 2012;81:3900-3904

16. Weinsaft JW, Kim J, Medicherla CB, Ma CL, Codella NC, Kukar N, Alaref S, Kim RJ, Devereux RB. Echocardiographic algorithm for post-myocardial infarction lv thrombus: A gatekeeper for thrombus evaluation by delayed enhancement cmr. JACC Cardiovasc Imaging . 2016;9:505-515

17. Weinsaft JW, Kim HW, Shah DJ, Klem I, Crowley AL, Brosnan R, James OG, Patel MR, Heitner J, Parker M, Velazquez EJ, Steenbergen C, Judd RM, Kim RJ. Detection of left ventricular thrombus by delayed-enhancement cardiovascular magnetic resonance prevalence and markers in patients with systolic dysfunction. J Am Coll Cardiol . 2008;52:148-157

18. Gellen B, Biere L, Logeart D, Lairez O, Vicaut E, Furber A, Mercadier JJ, Sirol M. Timing of cardiac magnetic resonance imaging impacts on the detection rate of left ventricular thrombus after myocardial infarction. JACC Cardiovasc Imaging . 2017;10:1404-1405

19. Meurin P, Brandao Carreira V, Dumaine R, Shqueir A, Milleron O, Safar B, Perna S, Smadja C, Genest M, Garot J, Carette B, Payot L, Tabet JY, College National des Cardiologues F, College National 
des Cardiologues des Hopitaux Francais PF. Incidence, diagnostic methods, and evolution of left ventricular thrombus in patients with anterior myocardial infarction and low left ventricular ejection fraction: A prospective multicenter study. Am Heart J . 2015;170:256-262

20. Ibanez B, James S, Agewall S, Antunes MJ, Bucciarelli-Ducci C, Bueno H, Caforio ALP, Crea F, Goudevenos JA, Halvorsen S, Hindricks G, Kastrati A, Lenzen MJ, Prescott E, Roffi M, Valgimigli M, Varenhorst C, Vranckx P, Widimsky P, Group ESCSD. 2017 esc guidelines for the management of acute myocardial infarction in patients presenting with st-segment elevation: The task force for the management of acute myocardial infarction in patients presenting with st-segment elevation of the european society of cardiology (esc). Eur Heart J . 2018;39:119-177

21. McCarthy CP, Vaduganathan M, McCarthy KJ, Januzzi JL, Jr., Bhatt DL, McEvoy JW. Left ventricular thrombus after acute myocardial infarction: Screening, prevention, and treatment. JAMA Cardiol . 2018;3:642-649

22. Weinsaft JW, Kim HW, Crowley AL, Klem I, Shenoy C, Van Assche L, Brosnan R, Shah DJ, Velazquez EJ, Parker M, Judd RM, Kim RJ. Lv thrombus detection by routine echocardiography: Insights into performance characteristics using delayed enhancement cmr. JACC Cardiovasc Imaging . 2011;4:702-712

23. Anwar AM, Nosir YF, Ajam A, Chamsi-Pasha H. Central role of real-time three-dimensional echocardiography in the assessment of intracardiac thrombi. Int J Cardiovasc Imaging . 2010;26:519-526

24. Duncan K, Nanda NC, Foster WA, Mehmood F, Patel V, Singh A. Incremental value of live/real time three-dimensional transthoracic echocardiography in the assessment of left ventricular thrombi.Echocardiography . 2006;23:68-72

25. Porter TR, Mulvagh SL, Abdelmoneim SS, Becher H, Belcik JT, Bierig M, Choy J, Gaibazzi N, Gillam LD, Janardhanan R, Kutty S, Leong-Poi H, Lindner JR, Main ML, Mathias W, Jr., Park MM, Senior R, Villanueva F. Clinical applications of ultrasonic enhancing agents in echocardiography: 2018 american society of echocardiography guidelines update. J Am Soc Echocardiogr . 2018;31:241-274

26. Bulluck H, Vincent M, Hausenloy DJ. Optimizing the detection of left ventricular thrombus following acute myocardial infarction in the current era. JAMA Cardiol . 2018;3:1128-1129

27. Velangi PS, Choo C, Chen KA, Kazmirczak F, Nijjar PS, Farzaneh-Far A, Okasha O, Akcakaya M, Weinsaft JW, Shenoy C. Long-term embolic outcomes after detection of left ventricular thrombus by late gadolinium enhancement cardiovascular magnetic resonance imaging: A matched cohort study. Circ Cardiovasc Imaging . 2019;12:e00723

28. Chen PF, Tang L, Yi JL, Pei JY, Hu XQ. The prognostic effect of left ventricular thrombus formation after acute myocardial infarction in the contemporary era of primary percutaneous coronary intervention: A meta-analysis. Eur J Intern Med . 2020;73:43-50

29. Komrad MS, Coffey CE, Coffey KS, McKinnis R, Massey EW, Califf RM. Myocardial infarction and stroke. Neurology . 1984;34:1403-1409

30. Mooe T, Eriksson P, Stegmayr B. Ischemic stroke after acute myocardial infarction. A population-based study. Stroke . 1997;28:762-767

31. Visser CA, Kan G, Meltzer RS, Dunning AJ, Roelandt J. Embolic potential of left ventricular thrombus after myocardial infarction: A two-dimensional echocardiographic study of 119 patients. J Am Coll Cardiol . 1985;5:1276-1280

32. Meltzer RS, Visser CA, Fuster V. Intracardiac thrombi and systemic embolization. Ann Intern Med . 1986;104:689-698

33. Haugland JM, Asinger RW, Mikell FL, Elsperger J, Hodges M. Embolic potential of left ventricular thrombi detected by two-dimensional echocardiography. Circulation . 1984;70:588-598 
34. Domenicucci S, Bellotti P, Chiarella F, Lupi G, Vecchio C. Spontaneous morphologic changes in left ventricular thrombi: A prospective two-dimensional echocardiographic study. Circulation . 1987;75:737-743

35. O'Gara PT, Kushner FG, Ascheim DD, Casey DE, Jr., Chung MK, de Lemos JA, Ettinger SM, Fang JC, Fesmire FM, Franklin BA, Granger CB, Krumholz HM, Linderbaum JA, Morrow DA, Newby LK, Ornato JP, Ou N, Radford MJ, Tamis-Holland JE, Tommaso CL, Tracy CM, Woo YJ, Zhao DX. 2013 accf/aha guideline for the management of st-elevation myocardial infarction: A report of the american college of cardiology foundation/american heart association task force on practice guidelines. J Am Coll Cardiol . 2013;61:e78-e140

36. Guyatt GH, Akl EA, Crowther M, Gutterman DD, Schuunemann HJ, American College of Chest Physicians Antithrombotic T, Prevention of Thrombosis P. Executive summary: Antithrombotic therapy and prevention of thrombosis, 9th ed: American college of chest physicians evidence-based clinical practice guidelines. Chest . 2012;141:7S-47S

37. Vaitkus PT, Barnathan ES. Embolic potential, prevention and management of mural thrombus complicating anterior myocardial infarction: A meta-analysis. J Am Coll Cardiol . 1993;22:1004-1009

38. Maniwa N, Fujino M, Nakai M, Nishimura K, Miyamoto Y, Kataoka Y, Asaumi Y, Tahara Y, Nakanishi M, Anzai T, Kusano K, Akasaka T, Goto Y, Noguchi T, Yasuda S. Anticoagulation combined with antiplatelet therapy in patients with left ventricular thrombus after first acute myocardial infarction. Eur Heart $J$. 2018;39:201-208

39. Lopes RD, Hong H, Harskamp RE, Bhatt DL, Mehran R, Cannon CP, Granger CB, Verheugt FWA, Li J, Ten Berg JM, Sarafoff N, Gibson CM, Alexander JH. Safety and efficacy of antithrombotic strategies in patients with atrial fibrillation undergoing percutaneous coronary intervention: A network meta-analysis of randomized controlled trials.JAMA Cardiol . 2019;4:747-755

40. Kajy M, Shokr M, Ramappa P. Use of direct oral anticoagulants in the treatment of left ventricular thrombus: Systematic review of current literature. Am J Ther . 2019

41. Fleddermann AM, Hayes CH, Magalski A, Main ML. Efficacy of direct acting oral anticoagulants in treatment of left ventricular thrombus. Am J Cardiol . 2019;124:367-372

42. Tomasoni D, Sciatti E, Bonelli A, Vizzardi E, Metra M. Direct oral anticoagulants for the treatment of left ventricular thrombus - a new indication? A meta-summary of case reports doacs in left ventricular thrombosis. J Cardiovasc Pharmacol . 2020

43. Robinson AA, Trankle CR, Eubanks G, Schumann C, Thompson P, Wallace RL, Gottiparthi S, Ruth B, Kramer CM, Salerno M, Bilchick KC, Deen C, Kontos MC, Dent J. Off-label use of direct oral anticoagulants compared with warfarin for left ventricular thrombi. JAMA Cardiol . 2020

44. Zannad F, Anker SD, Byra WM, Cleland JGF, Fu M, Gheorghiade M, Lam CSP, Mehra MR, Neaton JD, Nessel CC, Spiro TE, van Veldhuisen DJ, Greenberg B, Investigators CH. Rivaroxaban in patients with heart failure, sinus rhythm, and coronary disease. N Engl J Med . 2018;379:1332-1342 


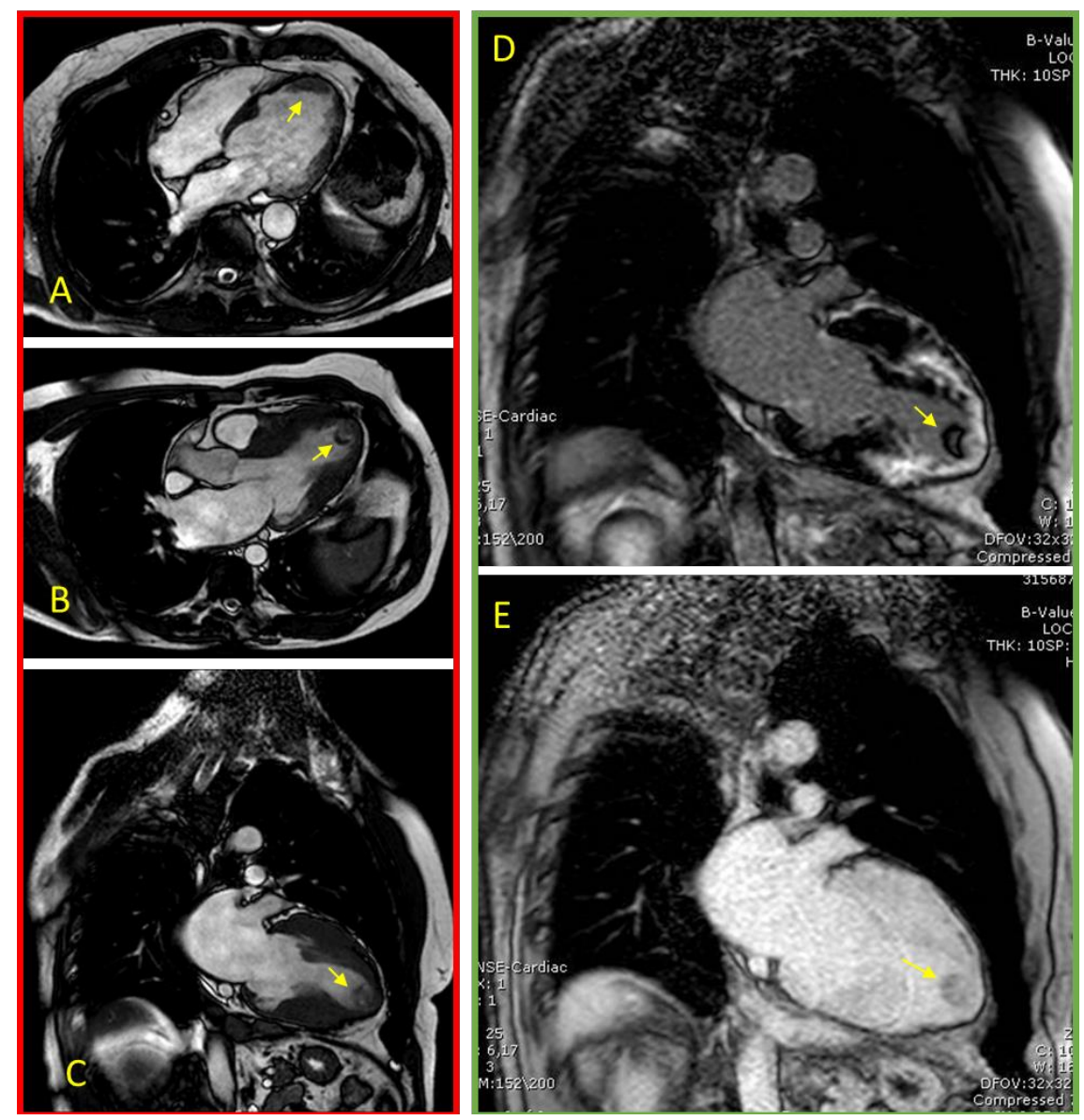



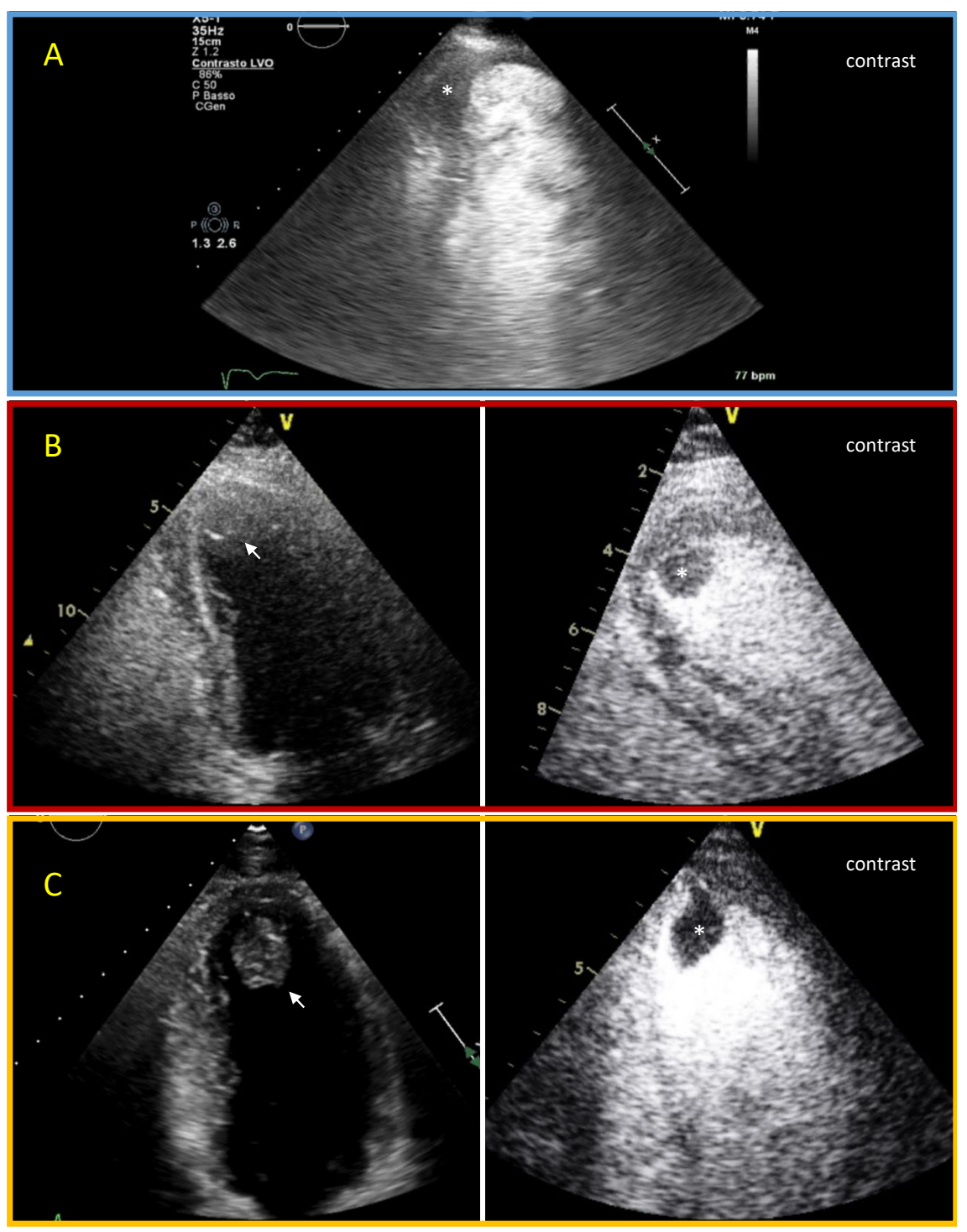

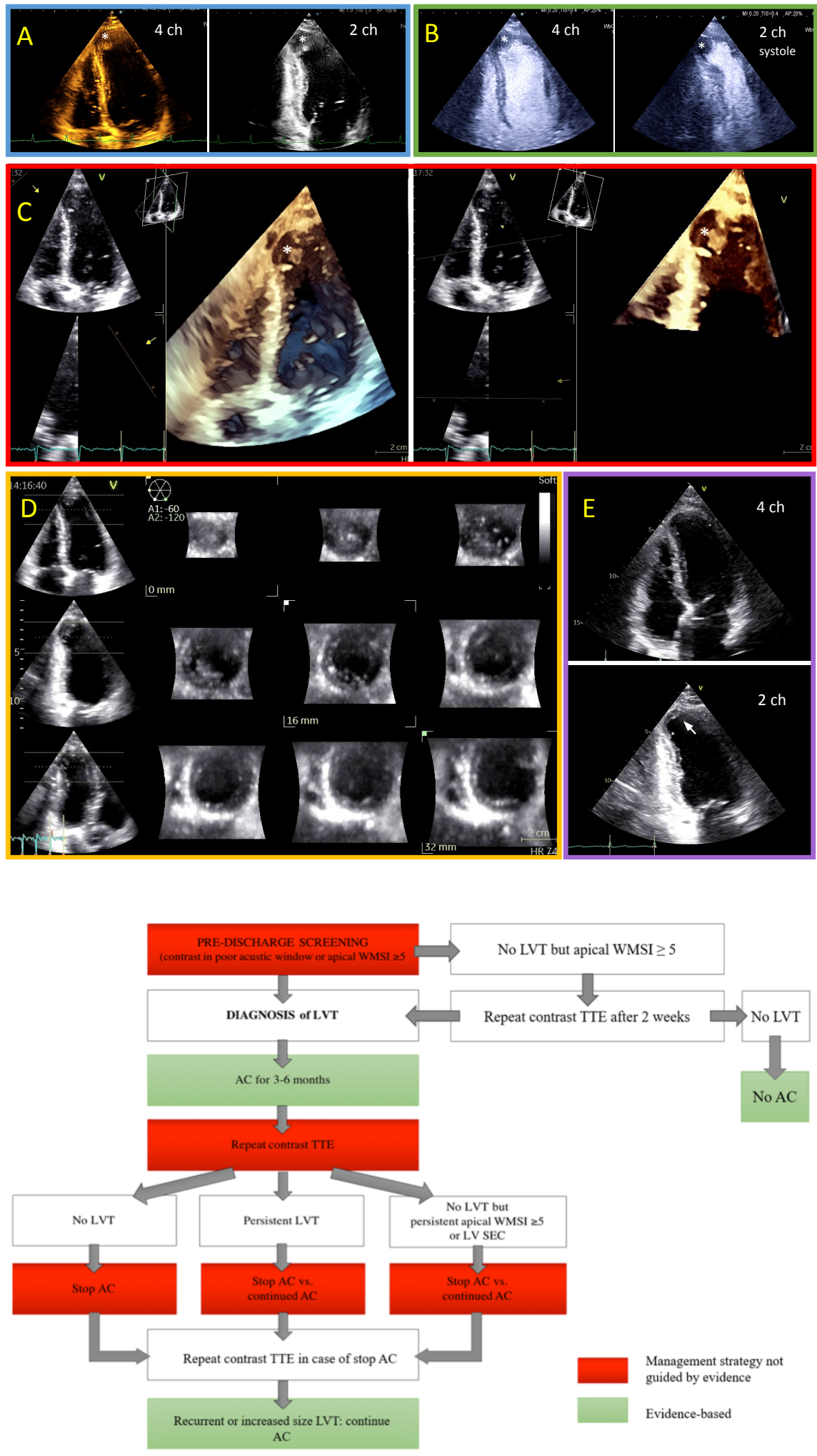